\title{
Multiple Positive Solutions of the Singular Boundary Value Problem for Second-Order Impulsive Differential Equations on the Half-Line
}

\author{
Jing Xiao, ${ }^{1}$ Juan J. Nieto, ${ }^{2}$ and Zhiguo Luo ${ }^{1}$ \\ ${ }^{1}$ Department of Mathematics, Hunan Normal University, Changsha, Hunan 410081, China \\ ${ }^{2}$ Departamento de Análisis Matemático, Facultad de Matemáticas, Universidad de Santiago de Compostela, \\ 15782 Santiago de Compostela, Spain
}

Correspondence should be addressed to Zhiguo Luo, luozg@hunnu.edu.cn

Received 17 November 2009; Revised 22 January 2010; Accepted 21 February 2010

Academic Editor: Claudianor Alves

Copyright (C) 2010 Jing Xiao et al. This is an open access article distributed under the Creative Commons Attribution License, which permits unrestricted use, distribution, and reproduction in any medium, provided the original work is properly cited.

This paper uses a fixed point theorem in cones to investigate the multiple positive solutions of a boundary value problem for second-order impulsive singular differential equations on the halfline. The conditions for the existence of multiple positive solutions are established.

\section{Introduction}

Consider the following nonlinear singular Sturm-Liouville boundary value problems for second-order impulsive differential equation on the half-line:

$$
\begin{gathered}
\left(p(t) u^{\prime}(t)\right)^{\prime}+f(t, u)=0, \quad \forall t \in J_{+}^{\prime}, \\
\Delta u^{\prime}\left(t_{k}\right)=I_{k}\left(u\left(t_{k}\right)\right), \quad k=1,2, \ldots, n, \\
\alpha u(0)-\beta \lim _{t \rightarrow 0^{+}} p(t) u^{\prime}(t)=0, \\
r u(\infty)+\delta \lim _{t \rightarrow+\infty} p(t) u^{\prime}(t)=0,
\end{gathered}
$$

where $J=[0,+\infty), 0<t_{1}<\cdots<t_{n}, J_{+}=(0,+\infty), J_{+}^{\prime}=J_{+} \backslash\left\{t_{1}, \ldots, t_{n}\right\}, f \in C\left[J_{+} \times J_{+}, J_{+}\right]$, $p \in C\left[J, J_{+}\right] \cap C^{1}\left[J_{+}, J_{+}\right]$with $p>0$ on $J_{+}$, and $\int_{0}^{+\infty}(1 / p(s)) d s<+\infty ; \alpha, \beta, \gamma, \delta \geq 0$ with $\rho=\beta \gamma+\alpha \delta+\alpha \gamma B(0,+\infty)>0$, in which $B(t, s)=\int_{t}^{s}(1 / p(\sigma)) d \sigma . \Delta u^{\prime}\left(t_{k}\right)=u^{\prime}\left(t_{k}^{+}\right)-u^{\prime}\left(t_{k}^{-}\right)$, 
where $u^{\prime}\left(t_{k}^{-}\right)$and $u^{\prime}\left(t_{k}^{+}\right)$are, respectively, the left and right limits of $u^{\prime}(t)$ at $t_{k}, k=1, \ldots, n$, $1 \leq n<+\infty$.

The theory of singular impulsive differential equations has been emerging as an important area of investigation in recent years. For the theory and classical results, we refer the monographs to [1,2] and the papers [3-19] to readers. We point out that in a second-order differential equation $u^{\prime \prime}=f\left(t, u, u^{\prime}\right)$, one usually considers impulses in the position $u$ and the velocity $u^{\prime}$. However, in the motion of spacecraft one has to consider instantaneous impulses depending on the position that result in jump discontinuities in velocity, but with no change in position [20]. The impulses only on the velocity occur also in impulsive mechanics [21].

In recent paper [3], by using the Krasnoselskii's fixed point theorem, Kaufmann has discussed the existence of solutions for some second-order boundary value problem with impulsive effects on an unbounded domain. In [22] Sun et al. and [23] Liu et al., respectively, discussed the existence and multiple positive solutions for singular SturmLiouville boundary value problems for second-order differential equation on the half-line. But the Multiple positive solutions of this case with both singularity and impulses are not to be studied. The aim of this paper is to fill up this gap.

The rest of the paper is organized as follows. In Section 2, we give several important lemmas. The main theorems are formulated and proved in Section 3. And in Section 4, we give an example to demonstrate the application of our results.

\section{Several Lemmas}

Lemma 2.1 (see [23]). If conditions $\int_{0}^{+\infty}(1 / p(s)) d s<+\infty$ and $\rho>0$ are satisfied, then the boundary value problem

$$
\begin{gathered}
\left(p(t) u^{\prime}(t)\right)^{\prime}+v(t)=0, \quad \forall t \in J_{+}, \\
\alpha u(0)-\beta \lim _{t \rightarrow 0^{+}} p(t) u^{\prime}(t)=0, \\
\gamma u(\infty)+\delta \lim _{t \rightarrow+\infty} p(t) u^{\prime}(t)=0
\end{gathered}
$$

has a unique solution for any $v \in L\left[J_{+}, R\right]$. Moreover, this unique solution can be expressed in the form

$$
u(t)=\int_{0}^{\infty} G(t, s) v(s) d s,
$$

where $G(t, s)$ is defined by

$$
G(t, s)=\frac{1}{\rho} \begin{cases}(\beta+\alpha B(0, s))(\delta+\gamma B(t, \infty)), & 0 \leq s \leq t<+\infty \\ (\beta+\alpha B(0, t))(\delta+\gamma B(s, \infty)), & 0 \leq t \leq s<+\infty\end{cases}
$$


Remark 2.2. It is easy to prove that $G(t, s)$ has the following properties:

(1) $G(t, s)$ is continuous on $J_{+} \times J_{+}$,

(2) $G(t, s)$ is continuous differentiable on $J_{+} \times J_{+}$, except $t=s$,

(3) $\left.\partial_{t} G(t, s)\right|_{t=s^{+}}-\left.\partial_{t} G(t, s)\right|_{t=s^{-}}=(p(s))^{-1}$,

(4) $G(t, s) \leq G(s, s) \leq \rho^{-1}(\beta+\alpha B(0, s))(\delta+\gamma B(s, \infty))<+\infty$,

(5) $\bar{G}(s)=\lim _{t \rightarrow+\infty} G(t, s)<+\infty$,

(6) for all $t \in[a, b] \subset(0,+\infty), s \in[0,+\infty), G(t, s) \geq \omega G(s, s)$, where

$$
w=\min \left\{\frac{\beta+\alpha B(b, \infty)}{\beta+\alpha B(0, \infty)}, \frac{\delta+\gamma B(b, \infty)}{\delta+\gamma B(0, \infty)}\right\}
$$

Obviously, $0<\omega<1$.

For the interval $[a, b], 0<a<t_{1}, t_{n}<b<\infty$, and the corresponding $\omega$ in Remark 2.2, we define $P C^{1}[J, R]=\left\{u \in C[J, R]: u^{\prime} \in C\left[J_{+}^{\prime}, R\right], u^{\prime}\left(t_{k}^{-}\right)\right.$and $u^{\prime}\left(t_{k}^{+}\right)$exist, and $\left.u^{\prime}\left(t_{k}\right)=u^{\prime}\left(t_{k}^{-}\right)\right\}$. $B P C^{1}[J, R]=\left\{u \in P C^{1}[J, R]: \lim _{t \rightarrow \infty} u(t)\right.$ exists $\} . K=\left\{u \in B P C^{1}[J, R]: u(t)>0, t \in J_{+}\right.$ and $\left.\min _{t \in[a, b]} u(t) \geq \omega\|u\|\right\}$. It is easy to see that $B P C^{1}[J, R]$ is a Banach space with the norm $\|u\|=\sup _{t \in J}|u(t)|$, and $K$ is a positive cone in $B P C^{1}[J, R]$. For details of the cone theory, see [1]. $u \in P C^{1}[J, R] \cap C^{2}\left[J_{+}^{\prime} R\right]$ is called a positive solution of BVP (1.1) if $u(t)>0$ for all $t \in J$ and $u(t)$ satisfies (1.1).

As we know that the Ascoli-Arzela Theorem does not hold in infinite interval $J$, we need the following compactness criterion:

Lemma 2.3 (see [22]). Let $M \subset B P C^{1}[J, R]$. Then $M$ is relatively compact in $B P C^{1}[J, R]$ if the following conditions hold.

(i) $M$ is uniformly bounded in $B P C^{1}[J, R]$.

(ii) The functions from $M$ are equicontinuous on any compact interval of $[0,+\infty)$.

(iii) The functions from $M$ are equiconvergent, that is, for any given $\varepsilon>0$, there exists a $T=T(\varepsilon)>0$ such that $|f(t)-f(+\infty)|<\varepsilon$, for any $t>T, f \in M$.

The main tool of this work is a fixed point theorem in cones.

Lemma 2.4 (see [4]). Let $X$ be a Banach space and $K$ is a positive cone in X. Assume that $\Omega_{1}, \Omega_{2}$ are open subsets of $X$ with $0 \in \Omega_{1}, \bar{\Omega}_{1} \subset \Omega_{2}$. Let $T: K \cap\left(\bar{\Omega}_{2} \backslash \Omega_{1}\right) \rightarrow K$ be a completely continuous operator such that

(i) $\|T u\| \leq\|u\|$ for all $u \in K \cap \partial \Omega_{1}$.

(ii) there exists $a \Phi \in K$ such that $u \neq T u+\lambda \Phi$, for all $u \in K \cap \partial \Omega_{2}$ and $\lambda>0$.

Then $T$ has a fixed point in $K \cap\left(\bar{\Omega}_{2} \backslash \Omega_{1}\right)$.

Remark 2.5. If (i) is satisfied for $u \in K \cap \partial \Omega_{2}$ and (ii) is satisfied for $u \in K \cap \partial \Omega_{1}$, then Lemma 2.4 is still true. 
Lemma 2.6 (see [3]). The function $u \in K \cap C^{2}\left[J_{+}^{\prime}, R\right]$ is a solution of the $B V P$ (1.1) if and only if $u \in K$ satisfies the equation

$$
u(t)=\int_{0}^{+\infty} G(t, s) f(s, u(s)) d s+\sum_{k=1}^{n} G\left(t, t_{k}\right) p\left(t_{k}\right) I_{k}\left(u\left(t_{k}\right)\right), \quad t \in J .
$$

The proof of this result is based on the properties of the Green function, so we omit it as elementary.

Define

$$
(T u)(t)=\int_{0}^{+\infty} G(t, s) f(s, u(s)) d s+\sum_{k=1}^{n} G\left(t, t_{k}\right) p\left(t_{k}\right) I_{k}\left(u\left(t_{k}\right)\right), \quad t \in J .
$$

Obviously, the BVP (1.1) has a solution $u$ if and only if $u \in K$ is a fixed point of the operator $T$ defined by (2.6).

Let us list some conditions as follows.

$\left(A_{1}\right)$ There exist two nonnegative functions: $a \in C\left[J_{+}, J\right], g \in C[J, J]$ such that $f(t, u) \leq$ $a(t) g(u) . f(t, u), a(t)$ may be singular at $t=0$. $I_{k}: J \rightarrow J, k=1, \ldots, n$, are continuous.

$\left(A_{2}\right) 0<\int_{0}^{+\infty} G(s, s) a(s) d s<+\infty, 0<G\left(t_{k}, t_{k}\right) p\left(t_{k}\right)<+\infty, k=1, \ldots, n$.

Lemma 2.7. If $\left(A_{1}\right)$ and $\left(A_{2}\right)$ are satisfied, then for any bounded open set $\Omega \subset B P C^{1}[J, R], T$ : $\bar{\Omega} \cap K \rightarrow K$ is a completely continuous operator.

Proof. For any bounded open set $\Omega \subset B P C^{1}[J, R]$, there exists a constant $M>0$ such that $\|u\| \leq M$ for any $u \in \bar{\Omega}$.

First, we show that $T: \bar{\Omega} \cap K \rightarrow K$ is well defined. Let $u \in \bar{\Omega} \cap K$. From $\left(A_{1}\right)$, we have $S_{M}=\max \left\{S_{1}, S_{2}\right\}$, where $S_{1}=\sup \{g(u): 0 \leq u \leq M\}, S_{2}=\sup \left\{I_{k}(u): 0 \leq u \leq M\right.$, $k=1, \ldots, n\}$, and

$$
\begin{aligned}
& \int_{0}^{+\infty} G(t, s) f(s, u(s)) d s+\sum_{k=1}^{n} G\left(t, t_{k}\right) p\left(t_{k}\right) I_{k}\left(u\left(t_{k}\right)\right) \\
& \quad \leq S_{M}\left(\int_{0}^{+\infty} G(s, s) a(s) d s+\sum_{k=1}^{n} G\left(t_{k}, t_{k}\right) p\left(t_{k}\right)\right)<+\infty .
\end{aligned}
$$

Hence, $T$ is well defined. For any $t_{1}, t_{2} \in J$, we have

$$
\int_{0}^{+\infty}\left|G\left(t_{1}, s\right)-G\left(t_{2}, s\right)\right| a(s) d s \leq 2 \int_{0}^{+\infty} G(s, s) a(s) d s<+\infty
$$


Thus, by the Lebesgue dominated convergence theorem and the fact that $G(s, t)$ is continuous on $t$, we have, for any $t_{1}, t_{2} \in J, u \in \bar{\Omega} \cap K$,

$$
\begin{aligned}
& \left|(T u)\left(t_{1}\right)-(T u)\left(t_{2}\right)\right| \\
& \leq \int_{0}^{+\infty}\left|G\left(t_{1}, s\right)-G\left(t_{2}, s\right)\right| f(s, u(s)) d s \\
& \quad+\sum_{k=1}^{n}\left|G\left(t_{1}, t_{k}\right)-G\left(t_{2}, t_{k}\right)\right| p\left(t_{k}\right) I_{k}\left(u\left(t_{k}\right)\right) \\
& \leq S_{M}\left(\int_{0}^{+\infty}\left|G\left(t_{1}, s\right)-G\left(t_{2}, s\right)\right| a(s) d s+\sum_{\mathrm{k}=1}^{n}\left|G\left(t_{1}, t_{k}\right)-G\left(t_{2}, t_{k}\right)\right| p\left(t_{k}\right)\right) \\
& \longrightarrow 0, \quad\left(t_{1} \longrightarrow t_{2}\right) .
\end{aligned}
$$

Therefore, $T u \in C[J, R]$. By the property (3) of $G(s, t)$, it is easy to get $T u \in P C^{1}[J, R]$.

On the other hand, by (2.6) we have, for any $u \in \bar{\Omega} \cap K$ and $t \in J_{+}$,

$$
\begin{aligned}
\mid(T u)(\mathrm{t}) & -\int_{0}^{+\infty} \bar{G}(s) f(s, u(s)) d s \mid \\
& \leq \int_{0}^{+\infty}|G(t, s)-\bar{G}(s)| f(s, u(s)) d s+\sum_{k=1}^{n}\left|G\left(t, t_{k}\right)-\bar{G}\left(t_{k}\right)\right| p\left(t_{k}\right) I_{k}\left(u\left(t_{k}\right)\right) \\
& \leq S_{M}\left(\int_{0}^{+\infty}|G(t, s)-\bar{G}(s)| a(s) d s+\sum_{k=1}^{n}\left|G\left(t, t_{k}\right)-\bar{G}\left(t_{k}\right)\right| p\left(t_{k}\right)\right)
\end{aligned}
$$

Then by $\left(A_{2}\right)$, the property (5) of Remark 2.2 and the Lebesgue dominated convergence theorem, we have

$$
\lim _{t \rightarrow+\infty}(T u)(t)=\int_{0}^{+\infty} \bar{G}(s) f(s, u(s)) d s+\sum_{k=1}^{n} \bar{G}\left(t_{k}\right) p\left(t_{k}\right) I_{k}\left(u\left(t_{k}\right)\right)<+\infty
$$

Thus $T u \in B P C^{1}[J, R]$. 
For any $u \in \bar{\Omega} \cap K$, we get

$$
\begin{aligned}
(T u)(t) & =\int_{0}^{+\infty} G(t, s) f(s, u(s)) d s+\sum_{k=1}^{n} G\left(t, t_{k}\right) p\left(t_{k}\right) I_{k}\left(u\left(t_{k}\right)\right) \\
& \leq \int_{0}^{+\infty} G(s, s) f(s, u(s)) d s+\sum_{k=1}^{n} G\left(t_{k}, t_{k}\right) p\left(t_{k}\right) I_{k}\left(u\left(t_{k}\right)\right) .
\end{aligned}
$$

So

$$
\|T u\| \leq \int_{0}^{+\infty} G(s, s) f(s, u(s)) d s+\sum_{k=1}^{n} G\left(t_{k}, t_{k}\right) p\left(t_{k}\right) I_{k}\left(u\left(t_{k}\right)\right) .
$$

On the other hand, for $t \in[a, b]$ we obtain

$$
(T u)(t) \geq \omega\left(\int_{0}^{+\infty} G(s, s) f(s, u(s)) d s+\sum_{k=1}^{n} G\left(t_{k}, t_{k}\right) p\left(t_{k}\right) I_{k}\left(u\left(t_{k}\right)\right)\right) \geq \omega\|T u\| .
$$

Thus $T: \bar{\Omega} \cap K \rightarrow K$.

Next, we prove that $T$ is continuous. Let $u_{n} \rightarrow u_{0}$ in $\bar{\Omega} \cap K$, then $\left\|u_{n}\right\| \leq M(n=$ $1,2, \ldots)$. We prove that $T u_{n} \rightarrow T u_{0}$. For any $\varepsilon>0$, by $\left(A_{2}\right)$, there exists a constant $A_{0}>0$ such that

$$
S_{M} \int_{A_{0}}^{+\infty} G(s, s) a(s) d s \leq \frac{\varepsilon}{6}
$$

On the other hand, by the continuities of $f(t, u)$ on $\left(0, A_{0}\right] \times(0, M]$ and the continuities of $I_{k}$ on $J$, for the above $\varepsilon>0$, there exists a $\delta>0$ such that, for any $u, v \in(0, M],|u-v|<\delta$,

$$
\begin{gathered}
|f(t, u)-f(t, v)|<\frac{\varepsilon}{3}\left(\int_{0}^{A_{0}} G(s, s) d s\right)^{-1}, \quad t \in\left(0, A_{0}\right] \\
G\left(t_{k}, t_{k}\right) p\left(t_{k}\right)\left|I_{k}\left(u\left(t_{k}\right)\right)-I_{k}\left(v\left(t_{k}\right)\right)\right|<\frac{\varepsilon}{3 n} .
\end{gathered}
$$

From $\left\|u_{n}-u_{0}\right\| \rightarrow 0$, for the above $\delta$, there exists a sufficiently large number $N$ such that, when $n>N$, we have

$$
\begin{gathered}
\left|u_{n}(t)-u_{0}(t)\right| \leq\left\|u_{n}-u_{0}\right\|<\delta, \quad t \in\left(0, A_{0}\right], \\
\left|u_{n}\left(t_{k}\right)-u_{0}\left(t_{k}\right)\right| \leq\left\|u_{n}-u_{0}\right\|<\delta .
\end{gathered}
$$


Therefore, by (2.15)-(2.17), we have, for $n>N$,

$$
\begin{aligned}
\left\|T u_{n}-T u_{0}\right\| \leq \int_{0}^{+\infty} G(s, s)\left|f\left(s, u_{n}(s)\right)-f\left(s, u_{0}(s)\right)\right| d s \\
\quad+\sum_{k=1}^{n} G\left(t_{k}, t_{k}\right) p\left(t_{k}\right)\left|I_{k}\left(u_{n}\left(t_{k}\right)\right)-I_{k}\left(u_{0}\left(t_{k}\right)\right)\right| \\
\leq 2 S_{M} \int_{A_{0}}^{+\infty} G(s, s) a(s) d s+\int_{0}^{A_{0}} G(s, s)\left|f\left(s, u_{n}(s)\right)-f\left(s, u_{0}(s)\right)\right| d s \\
\quad+\sum_{k=1}^{n} G\left(t_{k}, t_{k}\right) p\left(t_{k}\right)\left|I_{k}\left(u\left(t_{k}\right)\right)-I_{k}\left(u_{0}\left(t_{k}\right)\right)\right| \\
\leq \\
\leq \frac{\varepsilon}{3}+\frac{\varepsilon}{3}+\frac{\varepsilon}{3}=\varepsilon .
\end{aligned}
$$

This implies that the operator $T$ is continuous.

Finally we show that $T: \bar{\Omega} \cap K \rightarrow K$ is a compact operator. In fact for any bounded set $D \subset \bar{\Omega}$, there exists a constant $M_{1}>0$ such that $\|u\| \leq M_{1}$ for any $u \in D \cap K$. Hence, we obtain

$$
\|T u\| \leq S_{M_{1}}\left(\int_{0}^{+\infty} G(s, s) a(s) d s+\sum_{k=1}^{n} G\left(t_{k}, t_{k}\right) p\left(t_{k}\right)\right)<+\infty .
$$

Therefore, $T(D \cap K)$ is uniformly bounded in $B P C^{1}[J, R]$.

Given $r>0$, for any $u \in D \cap K$, as the proof of (2.9), we can get that $\{T u: u \in D \cap K\}$ are equicontinuous on $[0, r]$. Since $r>0$ is arbitrary, $\{T u: u \in D \cap K\}$ are locally equicontinuous on $J_{+}$. By $(2.6),\left(A_{1}\right),\left(A_{2}\right)$, and the Lebesgue dominated convergence theorem, we have

$$
\begin{aligned}
|T u(t)-T u(+\infty)| & \leq S_{M_{1}}\left(\int_{0}^{+\infty}|G(t, s)-\bar{G}(s)| a(s) d s+\sum_{k=1}^{n}\left|G\left(t, t_{k}\right)-\bar{G}\left(t_{k}\right)\right| p\left(t_{k}\right)\right) \\
& \longrightarrow 0, \quad(t \longrightarrow+\infty)
\end{aligned}
$$

Hence, the functions from $\{T u: u \in D \cap K\}$ are equiconvergent. By Lemma 2.3, we have that $\{T u: u \in D \cap K\}$ is relatively compact in $B P C^{1}[J, R]$. Therefore, $T: \bar{\Omega} \cap K \rightarrow K$ is completely continuous. This completed the proof of Lemma 2.7. 


\section{Main Results}

For convenience and simplicity in the following discussion, we use the following notations:

$$
\begin{array}{cl}
f_{0}=\liminf _{u \rightarrow 0} \min _{t \in[a, b]} \frac{f(t, u)}{u}, \quad g_{0}=\liminf _{u \rightarrow 0} \frac{g(u)}{u}, \quad I_{0}(k)=\liminf _{u \rightarrow 0} \frac{p\left(t_{k}\right) I_{k}(u)}{u}, \\
f_{\infty}=\liminf _{u \rightarrow \infty} \min _{t \in[a, b]} \frac{f(t, u)}{u}, \quad g_{\infty}=\liminf _{u \rightarrow \infty} \frac{g(u)}{u}, \quad I_{\infty}(k)=\liminf _{u \rightarrow \infty} \frac{p\left(t_{k}\right) I_{k}(u)}{u}, \\
I^{q}(k)=\limsup _{u \rightarrow q} \frac{p\left(t_{k}\right) I_{k}(u)}{u}, \quad g^{\infty}=\limsup _{u \rightarrow \infty} \frac{g(u)}{u}, \quad I^{\infty}(k)=\limsup _{u \rightarrow \infty} \frac{p\left(t_{k}\right) I_{k}(u)}{u}, \\
\limsup _{u \rightarrow q} \frac{g(u)}{u}, \quad g^{0}=\limsup _{u \rightarrow 0} \frac{g(u)}{u}, \quad I^{0}(k)=\limsup _{u \rightarrow 0} \frac{p\left(t_{k}\right) I_{k}(u)}{u},
\end{array}
$$

Theorem 3.1. Let $\left(A_{1}\right)$ and $\left(A_{2}\right)$ hold. Then the BVP (1.1) has at least two positive solutions satisfying $0<\left\|u_{1}\right\|<q<\left\|u_{2}\right\|$ if the following conditions hold:

$\left(H_{1}\right) \omega\left(f_{0} \int_{a}^{b} G(s, s) d s+\sum_{k=1}^{n} G\left(t_{k}, t_{k}\right) I_{0}(k)\right)>1, \omega\left(f_{\infty} \int_{a}^{b} G(s, s) d s+\sum_{k=1}^{n} G\left(t_{k}, t_{k}\right) \cdot I_{\infty}(k)\right)>$ 1 ,

$\left(H_{2}\right)$ there exists a $q>0$ such that $g^{q} \int_{0}^{+\infty} G(s, s) a(s) d s+\sum_{k=1}^{n} G\left(t_{k}, t_{k}\right) I^{q}(k)<1$, for all $\omega q \leq u \leq q$, a.e. $t \in[0,+\infty)$.

Proof. By the definition of $f_{0}$ and $I_{0}$, for any $\varepsilon>0$, there exist $r \in(0, q)$ such that

$$
\begin{gathered}
f(t, u) \geq(1-\varepsilon) f_{0} u, \quad \forall\|u\| \leq r, t \in[a, b], \\
p\left(t_{k}\right) I_{k}(u) \geq(1-\varepsilon) I_{0}(k) u, \\
(1-\varepsilon) \omega\left(f_{0} \int_{a}^{b} G(s, s) d s+\sum_{k=1}^{n} G\left(t_{k}, t_{k}\right) I_{0}(k)\right) \geq 1, \quad \forall\|u\| \leq r .
\end{gathered}
$$

Define the open sets

$$
\Omega_{r}=\left\{u \in B P C^{1}[J, R]:\|u\|<r\right\}
$$

Let $\Phi \equiv 1$, then $\Phi \in K$. Now we prove that

$$
u \neq T u+\lambda \Phi, \quad \forall u \in K \cap \partial \Omega_{r}, \lambda>0 .
$$


If not, then there exist $u_{0} \in K \cap \partial \Omega_{r}$ and $\lambda_{0}>0$ such that $u_{0}=T u_{0}+\lambda_{0} \Phi$. Let $\mu=\min _{t \in[a, b]} u_{0}(t)$, then for any $t \in[a, b]$, we have

$$
\begin{aligned}
u_{0}(t) & =\left(T u_{0}\right)(t)+\lambda_{0} \\
& =\int_{0}^{+\infty} G(t, s) f\left(s, u_{0}(s)\right) d s+\sum_{k=1}^{n} G\left(t, t_{k}\right) p\left(t_{k}\right) I_{k}\left(u_{0}\left(t_{k}\right)\right)+\lambda_{0} \\
& \geq \omega \int_{0}^{+\infty} G(s, s) f\left(s, u_{0}(s)\right) d s+\omega \sum_{k=1}^{n} G\left(t_{k}, t_{k}\right) p\left(t_{k}\right) I_{k}\left(u_{0}\left(t_{k}\right)\right)+\lambda_{0} \\
& >(1-\varepsilon) \mu \omega\left(f_{0} \int_{a}^{b} G(s, s) d s+\sum_{k=1}^{n} G\left(t_{k}, t_{k}\right) I_{0}(k)\right)+\lambda_{0} \\
& \geq \mu+\lambda_{0} .
\end{aligned}
$$

This implies $\mu>\mu+\lambda_{0}$, a contradiction. Therefore, (3.4) holds.

That by the definition of $f_{\infty}$ and $I_{\infty}$, for any $\varepsilon>0$ there exist $R>q$ such that

$$
\begin{gathered}
f(t, u) \geq(1-\varepsilon) f_{\infty} u, \quad \forall\|u\| \geq R, t \in[a, b] \\
p\left(t_{k}\right) I_{k}(u) \geq(1-\varepsilon) I_{\infty}(k) u, \\
(1-\varepsilon) \omega\left(f_{\infty} \int_{a}^{b} G(s, s) d s+\sum_{k=1}^{n} G\left(t_{k}, t_{k}\right) I_{\infty}(k)\right) \geq 1, \quad \forall\|u\| \geq R .
\end{gathered}
$$

Define the open sets:

$$
\Omega_{R}=\left\{u \in B P C^{1}[J, R]:\|u\|<R\right\} .
$$

As the proof of (3.4), we can get that

$$
u \neq T u+\lambda \Phi, \quad \forall x \in K \cap \partial \Omega_{R}, \lambda>0 .
$$

On the other hand, for any $\varepsilon>0$, choose $q$ in $\left(\mathrm{H}_{2}\right)$ such that

$$
(1+\varepsilon)\left(g^{q} \int_{0}^{+\infty} G(s, s) a(s) d s+\sum_{k=1}^{n} G\left(t_{k}, t_{k}\right) I^{q}(k)\right) \leq 1, \quad \omega q \leq u \leq q .
$$

By the definition of $g^{q}, I^{q}$, for the above $\varepsilon>0$, there exists $\delta>0$, when $u \in(q-\delta, q+\delta)$; thus, we have

$$
\begin{gathered}
g(u) \leq(1+\varepsilon) g^{q} u, \\
p\left(t_{k}\right) I_{k}(u) \leq(1+\varepsilon) I^{q}(k) u .
\end{gathered}
$$


Define

$$
\Omega_{q}=\left\{u \in B P C^{1}[J, R]:\|u\|<q\right\} .
$$

Then, for any $u \in K \cap \partial \Omega_{q}$ and $t \in[0,+\infty)$, we can obtain

$$
\begin{aligned}
(T u)(t) & =\int_{0}^{+\infty} G(t, s) f(s, u(s)) d s+\sum_{k=1}^{n} G\left(t, t_{k}\right) p\left(t_{k}\right) I_{k}\left(u\left(t_{k}\right)\right) \\
& \leq \int_{0}^{+\infty} G(s, s) a(s) g(u(s)) d s+\sum_{k=1}^{n} G\left(t_{k}, t_{k}\right) p\left(t_{k}\right) I_{k}\left(u\left(t_{k}\right)\right) \\
& \leq(1+\varepsilon)\left(g^{q} \int_{0}^{\infty} G(s, s) a(s) d s+\sum_{k=1}^{n} G\left(t_{k}, t_{k}\right) I^{q}(k)\right)\|u\| \\
& \leq\|u\| .
\end{aligned}
$$

Therefore, $\|T u\| \leq\|u\|$.

Thus, we can obtain the existence of two positive solutions $u_{1}$ and $u_{2}$ satisfying $0<$ $\left\|u_{1}\right\|<q<\left\|u_{2}\right\|$ by using Lemma 2.4 and Remark 2.5, respectively.

Using a similar proof of Theorem 3.1, we can get the following conclusions.

Theorem 3.2. Let $\left(A_{1}\right)$ and $\left(A_{2}\right)$ hold. Then the BVP (1.1) has at least two positive solutions satisfying $0<\left\|u_{1}\right\|<q<\left\|u_{2}\right\|$ if the following conditions hold:

$\left(H_{3}\right) g^{0} \int_{0}^{+\infty} G(s, s) a(s) d s+\sum_{k=1}^{n} G\left(t_{k}, t_{k}\right) I^{0}(k)<1, g^{\infty} \int_{0}^{+\infty} G(s, s) a(s) d s+\sum_{k=1}^{n} G\left(t_{k}\right) I^{\infty}(k)<$ 1 ,

$\left(H_{4}\right)$ there exists $q>0$ such that $\omega\left(f_{q} \int_{a}^{b} G(s, s) d s+\sum_{k=1}^{n} G\left(t_{k}, t_{k}\right) I_{q}(k)\right)>1$, for all $\omega q \leq u \leq$ q, a.e. $t \in[0,+\infty)$.

Corollary 3.3. In Theorems 3.1 and 3.2, if conditions $\left(H_{1}\right)$ and $\left(H_{3}\right)$ are replaced by $\left(H_{1}^{*}\right)$ and $\left(H_{3}^{*}\right)$, respectively, then the conclusions also hold.

$$
\begin{aligned}
& \left(H_{1}^{*}\right) f_{0}=+\infty, \text { or } \sum_{k=1}^{n} I_{0}(k)=+\infty ; f_{\infty}=+\infty \text { or } \sum_{k=1}^{n} I_{\infty}(k)=+\infty, \\
& \left(H_{3}^{*}\right) g^{\infty}=0, \sum_{k=1}^{n} I^{\infty}(k)=0, g^{0}=0, \sum_{k=1}^{n} I^{0}(k)=0 .
\end{aligned}
$$

Remark 3.4. Notice that, in the above conclusions, we suppose that the singularity only exist in $f(t, u)$, that is, $\|f(t, u)\| \rightarrow+\infty$ as $t \rightarrow 0$. If we permit $\|f(t, u)\| \rightarrow+\infty$ as $t \rightarrow 0^{+}$or $u \rightarrow 0^{+}$and $\left\|I_{k}\left(u_{k}\right)\right\| \rightarrow+\infty$ as $u_{k} \rightarrow 0^{+}$, then the discussion will be much more complex. Now we state the corresponding results.

Let us define the following.

$\left(A_{1}^{*}\right)$ There exist four nonnegative functions $a, g \in C\left[J_{+}, J\right], b, h \in C[J, J]$ such that $b(t) h(u) \leq f(t, u) \leq a(t) g(u)$, and $h(u)$ is nondecreasing on $J . I_{k}: J_{+} \rightarrow J$, $k=1, \ldots, n$, are continuous.

$\left(A_{2}^{*}\right) 0<\int_{0}^{+\infty} G(s, s) a(s) d s<+\infty, \int_{0}^{+\infty} G(s, s) b(s) d s \geq\left(u^{*} / \omega h^{*}\right), 0<G\left(t_{k}, t_{k}\right) p\left(t_{k}\right)<$ $+\infty, k=1, \ldots, n$, where $u^{*} \in K, h^{*}=h(0)$. 
Theorem 3.5. Suppose $\left(A_{1}^{*}\right)$ and $\left(A_{2}^{*}\right)$ hold, then the BVP (1.1) has at least two positive solutions satisfying $u^{*}<\left\|u_{1}\right\|<q<\left\|u_{2}\right\|$ if $\left(H_{1}\right)$ and $\left(H_{2}\right)$ hold.

Proof. Define $Q=\left\{u \in K: u(t) \geq u^{*}\right.$, for all $\left.t \in J\right\}$. We only need to proove $T: \bar{\Omega} \cap Q \rightarrow Q$ is a completely continuous operator. Then the rest of the proof is the same as that Theorem 3.1. Notice that

$$
(T u)(t) \geq \omega \int_{0}^{+\infty} G(s, s) f(s, u(s)) d s \geq \omega h^{*} \int_{0}^{+\infty} G(s, s) b(s) d s \geq u^{*}
$$

and change $S_{1}, S_{2}$ to $S_{1}=\sup \left\{g(u): u^{*} \leq u \leq M\right\}, S_{2}=\sup \left\{I_{k}(u): u^{*} \leq u \leq M, k=1 \ldots, n\right\}$, then the same as the proof of Lemma 2.7, it is easy to compute that $T: \bar{\Omega} \cap Q \rightarrow Q$ is a completely continuous operator.

Corresponding to Theorem 3.2 and Corollary 3.3, there are Theorem 3.6 and Corollary 3.7. We just list here without proof.

Theorem 3.6. Suppose $\left(A_{1}^{*}\right)$ and $\left(A_{2}^{*}\right)$ hold, then the BVP (1.1) has at least two positive solutions satisfying $u^{*}<\left\|u_{1}\right\|<q<\left\|u_{2}\right\|$, if $\left(H_{3}\right)$ and $\left(H_{4}\right)$ hold.

Corollary 3.7. In Theorems 3.5 and 3.6 , if conditions $\left(H_{1}\right)$ and $\left(H_{3}\right)$ are replaced by $\left(H_{1}^{*}\right)$ and $\left(H_{3}^{*}\right)$, respectively, then the conclusions also hold.

\section{Example}

To illustrate how our main results can be used in practice we present the following example.

Example 4.1. Consider the following boundary value problem:

$$
\begin{gathered}
\left(e^{t} u^{\prime}(t)\right)^{\prime}+|\ln t|=0, \quad \forall t \in J_{+}, \quad t \neq 1, \\
\left.\Delta u^{\prime}\right|_{t_{1}=1}=u^{2}(1), \\
u(0)=0, \quad u(\infty)=0 .
\end{gathered}
$$

Conclusion 1. BVP (4.1) has at least two positive solutions $u_{1}$, $u_{2}$ satisfying $0<\left\|u_{1}\right\|<1 / 2<$ $\left\|u_{2}\right\|$.

Proof. Let $p(t)=e^{t}, g(u)=1, f(t, u)=a(t)=|\ln t|, I(u)=u^{2}$. Then by simple computation we have

$$
G(t, s)= \begin{cases}\int_{0}^{s} e^{-\sigma} d \sigma \int_{t}^{+\infty} e^{-\sigma} d \sigma, & 0 \leq s \leq t<+\infty, \\ \int_{0}^{t} e^{-\sigma} d \sigma \int_{s}^{+\infty} e^{-\sigma} d \sigma, & 0 \leq t \leq s<+\infty,\end{cases}
$$


where $\rho=1$. Furthermore, $\int_{0}^{+\infty}(1 / p(\sigma)) d \sigma=\int_{0}^{+\infty} e^{-\sigma} d \sigma=1<+\infty$ and

$$
\begin{gathered}
0<\int_{0}^{+\infty} G(s, s) a(s) d s=\int_{0}^{+\infty}\left(1-e^{-s}\right) e^{-s}|\ln s| d s<+\infty \\
0<G\left(t_{1}, t_{1}\right) p\left(t_{1}\right)=1-e^{-1}<+\infty
\end{gathered}
$$

Let $[a, b]=[1,2] \subset(0,+\infty)$. Then $\omega=e^{-2}$. Thus $\left(A_{1}\right)$ and $\left(A_{2}\right)$ are satisfied. It is easy to get that $f_{0}=+\infty, I_{\infty}(1)=+\infty$. Let $q=1 / 2$. Then

$$
g^{q} \int_{0}^{+\infty} G(s, s) a(s) d s+\sum_{k=1}^{n} G\left(t_{k}, t_{k}\right) I^{q}(k)<1
$$

Hence, $\left(H_{1}^{*}\right)$ and $\left(H_{2}\right)$ are satisfied. Therefore, by Corollary 3.3, problem (4.1) has at least two positive solutions $u_{1}, u_{2}$ satisfying $0<\left\|u_{1}\right\|<1 / 2<\left\|u_{2}\right\|$. The proof is completed.

\section{Acknowledgment}

This work is supported by the National Nature Science Foundation of P. R.China (10871063) and Scientific Research Fund of Hunan Provincial Education Department (07A038), partially supported by Ministerio de Educacion y Ciencia and FEDER, Project MTM2007-61724, and by Xunta de Galicia and FEDER, project no.PGIDIT06PXIB207023PR.

\section{References}

[1] D. J. Guo and V. Lakshmikantham, Nonlinear Problems in Abstract Cones, vol. 5 of Notes and Reports in Mathematics in Science and Engineering, Academic Press, Boston, Mass, USA, 1988.

[2] R. P. Agarwal and D. O'Regan, Infinite Interval Problems for Differential, Difference and Integral Equations, Kluwer Academic Publishers, Dordrecht, The Netherlands, 2001.

[3] E. R. Kaufmann, N. Kosmatov, and Y. N. Raffoul, "A second-order boundary value problem with impulsive effects on an unbounded domain," Nonlinear Analysis: Theory, Methods E Applications, vol. 69, no. 9, pp. 2924-2929, 2008.

[4] X. Zhang, X. Li, D. Jiang, and K. Wang, "Multiplicity positive solutions to periodic problems for firstorder impulsive differential equations," Journal of Computers \& Mathematics with Applications, vol. 52, no. 6-7, pp. 953-966, 2006.

[5] D. Guo, "Existence of solutions for $n$th order impulsive integro-differential equations in a Banach space," vol. 47 , no. 2 , pp. 741-752.

[6] D. Guo, "Multiple positive solutions of a boundary value problem for $n$ th-order impulsive integrodifferential equations in a Banach space," Nonlinear Analysis: Theory, Methods E Applications, vol. 56, no. 7, pp. 985-1006, 2004.

[7] H. Zhang, L. Liu, and Y. Wu, "A unique positive solution for $n$ th-order nonlinear impulsive singular integro-differential equations on unbounded domains in Banach spaces," Applied Mathematics and Computation, vol. 203, no. 2, pp. 649-659, 2008.

[8] D. Guo, "Multiple positive solutions of a boundary value problem for $n$ th-order impulsive integrodifferential equations in Banach spaces," Nonlinear Analysis: Theory, Methods E Applications, vol. 63, no. 4, pp. 618-641, 2005.

[9] J. Sun and H. Chen, "Variational method to the impulsive equation with Neumann boundary conditions," Boundary Value Problems, vol. 2009, Article ID 316812, 17 pages, 2009.

[10] D. Guo, "Existence of positive solutions for $n$ th-order nonlinear impulsive singular integrodifferential equations in Banach spaces," Nonlinear Analysis: Theory, Methods \& Applications, vol. 68, no. 9, pp. 2727-2740, 2008. 
[11] X. Xian, D. O'Regan, and R. P. Agarwal, "Multiplicity results via topological degree for impulsive boundary value problems under non-well-ordered upper and lower solution conditions," Boundary Value Problems, vol. 2008, Article ID 197205, 21 pages, 2008.

[12] D. Guo, "Positive solutions of an infinite boundary value problem for $n$ th-order nonlinear impulsive singular integro-differential equations in Banach spaces," Nonlinear Analysis: Theory, Methods $\mathcal{E}$ Applications, vol. 70, no. 5, pp. 2078-2090, 2009.

[13] Y. Li and H. Zhang, "Extremal solutions of periodic boundary value problems for first-order impulsive integrodifferential equations of mixed-type on time scales," Boundary Value Problems, vol. 2007, Article ID 73176, 16 pages, 2007.

[14] H. Zhang, L. Liu, and Y. Wu, "Positive solutions for $n$ th-order nonlinear impulsive singular integrodifferential equations on infinite intervals in Banach spaces," Nonlinear Analysis: Theory, Methods $\mathcal{E}$ Applications, vol. 70, no. 2, pp. 772-787, 2009.

[15] X. Zhang, "Positive solutions of singular multipoint boundary value problems for systems of nonlinear second-order differential equations on infinite intervals in Banach spaces," Boundary Value Problems, vol. 2009, Article ID 978605, 22 pages, 2009.

[16] A. Arara, M. Benchohra, N. Hamidi, and J. J. Nieto, "Fractional order differential equations on an unbounded domain," Nonlinear Analysis: Theory, Methods \& Applications, vol. 72, no. 2, pp. 580-586, 2010.

[17] D. O’Regan, B. Yan, and R. P. Agarwal, "Solutions in weighted spaces of singular boundary value problems on the half-line," Journal of Computational and Applied Mathematics, vol. 205, no. 2, pp. 751$763,2007$.

[18] J. Chu and J. J. Nieto, "Recent existence results for second-order singular periodic differential equations," Boundary Value Problems, vol. 2009, Article ID 540863, 20 pages, 2009.

[19] J. Li and J. J. Nieto, "Existence of positive solutions for multipoint boundary value problem on the half-line with impulses," Boundary Value Problems, vol. 2009, Article ID 834158, 12 pages, 2009.

[20] X. Liu and A. R. Willms, "Impulsive controllability of linear dynamical systems with applications to maneuvers of spacecraft," Mathematical Problems in Engineering, vol. 2, no. 4, pp. 277-299, 1996.

[21] S. Pasquero, "Ideality criterion for unilateral constraints in time-dependent impulsive mechanics," Journal of Mathematical Physics, vol. 46, no. 11, Article ID 112904, 20 pages, 2005.

[22] Y. Sun, Y. Sun, and L. Debnath, "On the existence of positive solutions for singular boundary value problems on the half-line," Applied Mathematics Letters, vol. 22, no. 5, pp. 806-812, 2009.

[23] L. Liu, Z. Wang, and Y. Wu, "Multiple positive solutions of the singular boundary value problems for second-order differential equations on the half-line," Nonlinear Analysis: Theory, Methods $\mathcal{E}$ Applications, vol. 71, no. 7-8, pp. 2564-2575, 2009. 